\title{
How Well Can Arab EFL Learners Adequately Use Discourse Markers?
}

\author{
https://doi.org/10.33806/ijaes2000.20.2.4

Shehdeh Fareh Najib Jarad
University of Sharjah, UAE

\begin{abstract}
Discourse markers are words or phrases used in both speech and writing to signal relationships between discourse segments, including clauses, sentences and even larger portions of texts such as paragraphs. Their proper use in writing effectively contributes to textuality standards, particularly cohesion and coherence. On the other hand, learners' misuse, underuse or overuse of these markers may negatively impact the quality of the texts that these learners produce. This paper examined the ability of a group of Arab learners of English as a foreign language (ALEFL) from the University of Sharjah to recognize and produce discourse markers in written compositions. Using two elicitation techniques, the researchers collected data for this research from a sample of one hundred Arab learners studying English at the University of Sharjah. A test consisting of four parts was specially designed to evaluate participants' ability to recognize and produce discourse markers in context. In addition, two hundred compositions written by ALEFL were analyzed to investigate their ability to produce discourse markers. The data analysis revealed that the participants' ability to recognize and produce discourse markers was relatively low and their ability to recognize the functions of discourse markers in context was below expectations.
\end{abstract}

Keywords: Arab EFL learners, connective adjuncts, discourse markers, linking adjuncts

\section{Introduction}

This paper attempted to investigate the ability of Arab learners of English to recognize and use words and phrases such as those in bold in the following texts extracted from the Corpus of Contemporary American English (COCA):

1. This conclusion is somewhat misguided, however. While the Taylor principle is capable of producing a locally unique equilibrium, it is not sufficient to determine the price level. As Benhabib, Schmitt-Grohe, and Uribe (2002) show, the Taylor principle is not sufficient to generate a globally unique equilibrium because there is a zero lower bound on nominal interest rates. As a result, there is a second possible steady state with multiple equilibrium near that point. 12 Self-fulfilling inflations and deflations are possible as a result. The potential for self-fulfilling expectations is widely recognized in the literature. In fact, there are a number of proposals to rule out the alternative equilibria including shifting to a money growth target (Atkeson, Chari, \& Kehoe, 2009) or a commodity standard (Woodford, 2003). As Cochrane (2011) notes, 
however, attempts to rule out alternative equilibria require a conundrum. (2017, ACAD: American Economist, COCA)

2. ....behavior that creates risk and behavior that may create risk. That is, behavior that "risks creating a risk" is itself "risky" behavior. Thus, it is more intelligible to conceive of the crime of reckless endangerment as one prohibiting risky conduct rather than as one aimed at prohibiting the abstract "harm" of "risk creation." Indeed, the Model Penal Code and states that follow its example explicitly endorse the view that risk need not be created in this "abstract" sense for the crime of reckless endangerment to have been committed. However, if despite this one nevertheless maintains that reckless endangerment is a prohibition against " objective risk creation " rather than " risky behavior " (and is thus only explicable in terms of victim-facing justifications for punishment), then offenders should not be punished at all when such justifications do not pertain, however counterintuitive this implication might be...(2017, ACAD: Vanderbilt Law Review, COCA)

These words and phrases are more common in formal written English than in informal written or spoken English. Grammarians and researchers have used different terms to describe these words and phrases. For example, Quirk et al. (1985) called them conjuncts and classified them into seven types of semantic relations (pp. 440; 634). On the other hand, Biber et al. (2002, pp. 389-92) used the term linking adverbials, which connect and relate units of discourse of different sizes including sentences or units larger than sentences. Huddleston and Pullum (2002, p. 389) separated these words and phrases into two types of connective adjuncts: pure and impure. According to them, pure connectives (first(ly), in the first place, second(ly), in the second place, also, furthermore, likewise, besides, however, moreover, similarly, alternatively, either, in comparison, nor, by contrast, for example, for instance, in other words, by the way, incidentally, parenthetically) "have no other function than that of connecting their clause to the surrounding text (or context)". On the other hand, the impure connectives (nevertheless, nonetheless, still, though, yet, in that case, otherwise, then, accordingly, as a result, consequently, hence, in consequence, so, therefore, thus) combine this connecting function with a function of concession, condition or reason/result.

Carter and McCarthy (2006, p. 256) used the term linking adjuncts, which are used to "show a semantic relationship between two clauses or sentences or paragraphs." They classified these linking adjuncts into additive, resultative, contrastive, time, concessive, inference, summative, listing, and meta-textual. Unlike adverb subordinators, linking adverbs, according to Larsen-Freeman et al. (2016), "do not subordinate a clause; rather, they connect independent clauses (p. 545)." Following Halliday and Hassan's (1976) analysis of conjunctions as a kind of cohesive devices, Larsen-Freeman et al. (2016, p. 545), classified linking adverbs into four types: additive, adversative, causal, and sequential. 
The common positions for these words and phrases are at the beginning, in the middle, or at the end of a main clause. When they are placed at the beginning of a main clause, they may be preceded by either a period or semicolon. However, when they are positioned in the middle or at the end of a main clause, they are normally preceded by commas, as illustrated below:

3. Because victim-facing justifications focus on the harm that crimes cause to victims, they are, if valid, theoretically capable of justifying differential punishment. However, we will show that victim-facing justifications for punishment are not available for every instance of criminal misconduct. (2017, ACAD: Vanderbilt Law Review, COCA)

4. It is clear that the fact that Lynch's reckless actions caused Siela's death exposed him to much harsher legal penalties than those faced by Calderon. It is less clear, however, what justifies this discrepancy in severity, given that Lynch does not seem to have behaved any more culpably than Calderon. (2017, ACAD: Vanderbilt Law Review, COCA)

5. This article recognizes the thoughtful counterarguments and concerns that have been raised over the years. Those views have not led to consistent application of the Code, however. (2017, ACAD: The American Bankruptcy Law Journal, COCA)

Stylistically speaking, there is no consensus among grammarians with regard to the use of punctuation with these words and phrases, and, of course, usage guidelines change over time.

Following Fraser (1999), we will use the term discourse markers (hereafter, DMs) to refer to the conjuncts/linking adverbials/linking adjuncts which are used to establish linking relations such as contrast, addition, result, sequencing, etc. In Fraser's (1999) words, DMs are lexical expressions drawn primarily from the syntactic classes of conjunctions, adverbs, and prepositional phrases. With certain exceptions, they signal a relationship between the segment they introduce, S2, and the prior segment, S1. They have a core meaning which is procedural, not conceptual. (p. 950)

According to the above definition, DMs mark a two-place relation and do not contribute to the propositional meaning of sentence 1 and sentence 2 . Excluded from the present study are modal particles (just, maybe) as well as interjections such as oh, yes/yea, or no/nay which do not mark two-place relations either, but are "pragmatic idioms" in that they constitute entire, separate messages (Fraser 1999, p. 943).

Regardless of the various labels of DMs, it has become clear that they play a vital role in creating cohesive texts rather than a group of disconnected sentences. They are used to link ideas with each other and signal the relationships between them in both speech and writing. Moreover, they are frequently used in communication to guide the listener or reader in the direction of a conversation or an essay. For example, a speaker may use a discourse marker to indicate his intention to open a new topic, shift to a new point, come to conclusion, or express 
agreement or disagreement with certain ideas. Discourse markers can play different roles in discourse. They can express different intersentential relations. They can be adversative (however, nevertheless, but, although, on the contrary, despite), additive (moreover, furthermore), illative (to sum up, finally, in conclusion), illustrative (for example, such as, for instance), cause and effect (because, therefore, thus, hence, consequently), comparing (likewise, similarly, equally), emphasizing (above all, in particular, especially), or sequencing (first, second, finally, subsequently, then). They can also be used to generalize (on the whole, in general, broadly speaking, primarily), and to express attitude (honestly, frankly, I suppose, no doubt, I am afraid, to tell the truth, in my opinion; Quirk et al 1985:1314).The proper use of sentence connectives contribute to creating textuality in texts and to improving the quality of writing. It also contributes to the organization of ideas and making them sound more logical. For all these reasons, it is of paramount importance for students to have an adequate level of mastery in using DMs in both speech and writing in order to enable them to develop a more logical, argumentative and persuasive style of writing. The misuse of these devices in writing usually renders texts awkward and unacceptable.

Foreign learners of English often encounter different types of difficulties at the phonological, morphological, syntactic, semantic, pragmatic and discoursal levels. However, researchers in English as a foreign language and language pedagogy do not always accord these levels equal attention. The major difficulties that foreign learners usually encounter in learning English are more often than not investigated at the microlinguistic level rather than at the macrolinguistic one. This practice reflects the interest of language educators in building up the students' grammatical competence rather than their communicative one. In this respect, Svartvik (1980) observed that foreign language learners' mistakes are often corrected at lower language levels such as morphology and syntax, but their erroneous uses of DMs are often neglected although their impact on communication might be graver. This study is an attempt to examine the ability of Arab learners at the tertiary level to use DMs in writing at the levels of both recognition and production.

The study proceeds as follows. Section two presents the objectives of the study. A review of the related literature will be provided in section 3 . The research methodology will be detailed in section 4 . The findings of the study and a discussion of the results will be presented in section 5. Finally, section 6 will provide some conclusions and recommendations.

\section{Objectives of the study}

This study examined the competence of Arab learners of English in using DMs at the levels of recognition and production. It is an attempt to provide answers to the following questions.

1. What is the significance of using DMs in written communication?

2. What are the consequences of misusing, overusing, or underusing DMs?

3. How well can Arab learners of English recognize and use DMs in their writing? 
4. What implications to teaching EFL, textbook writing, curriculum design and testing may such a study have?

Given the assumption that the proper use of DMs contributes to the development of foreign/second language learners' discourse competence, Fareh (2014a) advocates a discourse approach to the teaching of English grammar since it focuses on the meanings of grammatical constructions within discourse, rather than on language as structure governed by rigid rules. Developing foreign language learners' competence in writing often necessitates enabling such learners to competently use different types of skills ranging from the mechanics of writing to higher level discourse and pragmatic skills. Language teachers at the secondary and tertiary levels often voice serious concerns regarding their students' quality of writing. These concerns are not unjustifiable. Across the Arab world, these learners are usually taught English by non-native speakers of English who, more often than not, are not well trained to teach writing properly because most of them hold degrees in English Language and Literature without any certificate in teaching language skills. What aggravates the situation is the fact that textbooks do not expose students to the process of writing and do not offer them guided instruction into this process. English language teachers are, therefore, more inclined to focus on other language skills that can be more readily taught and tested such as grammatical structures, vocabulary, spelling, pronunciation and some reading skills. These pedagogical practices may help students develop their grammatical competence rather than communicative or discourse competence. In this respect, Fareh (2014b) holds that:

This tendency might be ascribed to the fact that EFL teachers find it easier to focus on teaching at the micro-linguistic level, i.e. the mechanics of writing, spelling, punctuation and sentence structure rather than teaching at the discourse and pragmatic levels. Furthermore, this practice is often indirectly encouraged by the testing techniques and policies adopted in public schools, where the focus is usually on producing grammatically correct sentences that are free from spelling and punctuation mistakes. The outcomes of this process are usually undesirable and purpose defeating since this practice does not turn out communicatively competent language users, particularly in written expression (p. 924).

\section{Review of related literature}

The interest in investigating DMs emerged with the shift from sentence-based grammar to discourse-based grammar. Using language for communicative purposes is not restricted to producing grammatically well-formed sentences. In other words, the purpose of language teaching and learning is not only to develop the linguistic competence of learners. Rather, language teaching should focus on developing learners' communicative or discourse competence.

Several researchers have investigated the use of DMs by EFL learners of different linguistic backgrounds. For example, Faghih et al. (2013) investigated the impact of teaching DMs on improving students' reading comprehension. The 
findings of this study revealed that training students on the use of DMs had a positive impact on their reading comprehension. In a quantitative and qualitative study, Chen (2006) explored the use of conjunctive adverbials by Taiwanese MA TESOL students. The study revealed that students tended to slightly overuse connectors on word level, and that certain connectors (such as therefore, besides) were misused by some of the student writers. Catalán and Alba (2014) examined the ability of 228 Spanish learners of English as a foreign language to use sentence connectors in written essays and found out that those learners either completely omitted connectors, added unnecessary ones, or chose the wrong connectors.

The problems faced by Arab EFL learners in using DMs in academic essays were highlighted by researchers such as Al-Khuweileh and Al-Shoumali (2000), Al-Jamhoor (2001), Al-Hazmi (2006) and Umair (2011). Umair (2011), for example, examined the causes of the problems that Arab learners face in multiability academic English writing classes. The author attributed the problems to the organization of teaching materials and resources, time allocated to teaching English per week, students' attitudes and differences in their level of understanding. Moreover, Ezza (2010) analyzed the effect of educational policies on the quality of the students' writing and concluded that the problems faced by Arab EFL learners cannot be solely keyed to an inherent weakness in students' abilities to write. Rather, it is the educational policies pertaining to the number of students in each class and the use of outdated teaching methods that lead to poor writing quality.

Another study was conducted by Iseni et al. (2016) in which the researchers examined 30 compositions written by Arab learners in the twelfth grade in order to determine the role that DMs and cohesive devices play in their writings as well as the impact of such devices on the quality of writing. The findings of this study revealed that the frequency of using DMs was very low. Furthermore, it was found that learners misunderstood the functions of DMs and confused their use in spoken and written communication. These remarks reveal that the foreign language learners' competence is not confined to their ability to produce grammatically correct sentences that are free from spelling and punctuation errors. In fact, the rules that govern the production and processing of discourse include cohesion, coherence, logical development of ideas, proper use of connectives and DMs, cooperative principles, politeness principles and observance of contextual factors. Natural discourse is characterized by the frequent use of DMs or connectives that play a vital role in making texts comprehensible. The proper use of these DMs is usually a desirable feature of discourse. On the other hand, the overuse, underuse or misuse of DMs degrade the quality of writing in the foreign language.

What makes this piece of research different from the reviewed above is that it is not procedural, i.e., it does not only back up what we already know but it offers practical tips on how to teach DMs (see recommendations below). It also stands different in terms of scope (recognition and production) and sample size 


\section{Research methodology}

\subsection{Participants}

This study was conducted at the University of Sharjah, United Arab Emirates. Sixty-five females and thirty-five males were randomly selected as the participants of this study. They are college students ranging in age from nineteen to twenty-one years old. This shows homogeneity in terms of age, education and language proficiency. All participants gave consent for their data to be used for the purpose of this research by signing the consent form prior to data collection. All the participants fulfilled the university language proficiency requirement, which is a band score of 5 on the IELTS exam or a score of 500 on the TOEFL. Furthermore, they studied one or two courses in English such as English for Academic Purposes, Speech Communication and Technical Writing. One hundred students from four sections were selected to answer the data elicitation techniques. The total number of students was 112. The responses of 12 students were excluded because most of the respondents either did not complete the tests, or they just answered certain sections and neglected others.

\subsection{Data elicitation techniques}

In order to examine the participants' ability to recognize and produce DMs, the authors identified the major roles that DMs signal in discourse. The functions selected were: addition, explanation, illustration, comparison, contrast, cause, result, conclusion and attitude. Two specially designed questionnaires were used to elicit data from the participants of the study. The first part was designed to collect data pertaining to the ability of the participants to recognize DMs, whereas the other was designed to elicit data pertaining to their ability to actually use DMs in context. The recognition test consisted of three parts. Part A consisted of 27 multiple choice questions in which the participants were requested to circle the letter of the most appropriate discourse marker that best completes the stem sentence. The purpose of this section was to check whether or not the learners can recognize the appropriate connective. Each of the nine functions of DMs was represented by three of the most common markers used to represent this function. For example, the additive function was represented by furthermore, in addition, and moreover, whereas the illustrative function was represented by similarly, likewise, and for instance. The following are representative examples:

1. You are not allowed to use your phone here. , you have to switch it off when you are in the library.
a. Similar to
b. Likewise
c. In other words

2. We rarely think about breathing it is something we do automatically.
a. since
b. therefore
c. as a result

3. I have never been an enemy of democracy. essential for the well-being of new nations.
a. In general
b. On the contrary
c. In other words I consider it 
Example one represents the explanatory function where students are expected to select alternative c. The second item represents the function in which the DMs markers is used to represent a causal relationship and therefore, the answer is option a. Finally, example 3 represents the function of contrast and the correct answer is option $b$.

Part B of the recognition test consisted of 18 multiple choice items in which the participants were asked to circle the letter of the correct alternative a, b, c or d that best indicates the function of the underlined DMs in each item. In this part, each function was represented by two items as in the following examples:

1. The patient has no previous history of suicides. That is to say, the patient has not made any previous attempts.
a. Contrast
b. illustration
c. explanation
d. attitude

2. Our new supervisor can speak three languages. He has six years of experience as well.
a. result
b. attitude
c. addition
d. explanation

3. Math was hard for me in high school. Likewise, it is hard in college.
a. explanation
b. conclusion
c. contrast
d. comparison

The purpose of this part was to examine whether the learners can determine the function of a given discourse marker. To ensure the validity and reliability of the elicitation techniques, the researchers requested two language instructors to evaluate the relevance of the questionnaire to the purpose of the study. Their feedback was taken into consideration and as a result, certain items were modified or totally changed.

Finally, part $\mathrm{C}$ consisted of a paragraph that contains $12 \mathrm{DMs}$ and the participants were asked to underline each discourse marker/sentence connector used in the paragraph.

It is worth mentioning that the participants were asked to answer the three parts of the test in one hour. Furthermore, the recognition test was given after the production test in order to avoid any potential washback effect.

The second part of the data elicitation technique was designed to elicit data pertaining to the ability of the students to actually use DMs. The production test consisted of two parts. Part A consisted of 18 items in which the participants were asked to fill in the blank in each sentence with the most appropriate discourse marker from the list given to them at the beginning of the test. Two items represented each of the nine functions that DMs signal in communication. Students in this part are supposed to understand the context and select the most appropriate discourse marker that fills in the blank in each sentence. Moreover, part 2 of the production test consisted of 100 compositions written by the participants on different topics representing different paragraph patterns, including definition, comparison, argumentation, contrast and cause and effect. These compositions were analyzed in order to identify the DMs that students used and the frequency of each. 


\section{Findings and discussion}

\subsection{Recognition}

The ability of the Arab learners to recognize DMs was investigated in three different techniques as mentioned above. Table (1) below presents the percentages of correct responses in the three parts of the recognition test.

Table 1: Average and Percentage of correct responses in recognition

\begin{tabular}{|l|l|}
\hline Recognition test & $\%$ \\
\hline Multiple choice items & 54 \\
\hline Determining the Function of DMs & $47 \%$ \\
\hline Identifying the DM & $50 \%$ \\
\hline Average & $50 \%$ \\
\hline
\end{tabular}

A quick glance at Table (1) reveals that the overall percentage of the students' ability to recognize DMs in the three tasks is very low taking into account that the participants of the study have successfully fulfilled the university admission requirement of obtaining a score of 500 on the TOEFL or a band score of 5 on the IELTS. Furthermore, they have studied at least one or two English courses such as English for Academic Purposes, Speech Communication and/or Technical Writing. The overall percentage of correct answers is $50 \%$. This means that almost $50 \%$ of the students encountered a considerable level of difficulty in recognizing DMs. Table (1) reveals that the most difficult aspect of recognizing DMs was manifest in the students' ability to identify the functions of DMs in context. The percentage of correct answers was $47 \%$. This means that $53 \%$ of students encounter a serious difficulty in determining the roles of DMs in signaling relationships between sentences in a text. Moreover, they do not possess an adequate background knowledge about the roles that DMs play in developing coherent and cohesive texts. It is worth noting that the satisfactory performance percentage is $70 \%$ (equaling GPA 2 out of 4 ), which is the minimum requirement for graduation at the University of Sharjah.

The next most difficult aspect was identifying DMs in a text. The percentage of correct answers was 50\%. This result provides solid evidence that the concept of discourse marker is not clear to learners. This may be ascribed to the practices of teaching English at the secondary and tertiary levels of teaching English. Furthermore, such a finding may reveal that ELT textbooks do accord adequate attention to teaching DMs.

Finally, the least difficult aspect was recognizing DMs in multiple choice questions. The students' performance in this task, although relatively low, was a little higher than their performance in the other two tasks. The percentage of correct responses was $54 \%$. This means that $46 \%$ of the students were unable to select the most appropriate discourse marker that fills in a slot in a context. A 
certain percentage of the correct responses may be ascribed to chance since students were provided with three distractors for each item.

The overall students' awareness of the DMs and their functions was $50 \%$. This mastery level of such an essential component in both reading and writing is not adequate. In addition, it reflects a major defect in teaching practices and textbook contents. Recognition abilities usually develop earlier than production abilities in the process of language acquisition. This implies that the students' abilities to properly produce DMs in writing are expected to be lower than their ability to recognize them. This low level of performance is expected to reflect negatively on the students' ability to read and comprehend texts because they will be unable to recognize the functions of DMs in developing textual cohesion and coherence. This leads us to examine the performance of the participants in this study in producing DMs.

While the sample of participants consisted of both male and female, the results of the study indicated that gender did not affect the responses.

\subsection{Production}

The students' ability to produce DMs was assessed in two tasks. The first one consisted of 18 fill-in the blank items, whereas the second was free composition. The overall percentage of correct responses in the first task was 39\%. This means that $61 \%$ of the learners encountered difficulty in using DMs properly in context. In this task, the participants were asked to fill in the blank in each item with the suitable discourse marker from a list given to them at the beginning of the task. The major problem attested in the students' responses was their inability to distinguish between the functions of the given DMs from which they had to select. Furthermore, this low level of mastery points to the students' lack of familiarity with DMs and their functions in written discourse and their roles in building up textuality.

The performance of the students in the second task, which required them to write paragraphs and essays on various topics, was not better than their performance in the first task. The overall average of using DMs correctly was 6.8 (13\%). Table (2) below shows the frequency and percentage of using DMs according to the function that each one represents in context.

Table (2): Frequency of DMs in free composition

\begin{tabular}{|l|l|l|l|}
\hline & Function & Frequency & \% \\
\hline $\mathbf{1}$ & Addition & 309 & 45.44 \\
\hline $\mathbf{2}$ & Cause & 165 & 24.26 \\
\hline $\mathbf{3}$ & Contrast & 110 & 16.17 \\
\hline $\mathbf{4}$ & Illustration & 53 & 7.79 \\
\hline $\mathbf{5}$ & Result & 25 & 3.67 \\
\hline $\mathbf{6}$ & Conclusion & 14 & 2.05 \\
\hline $\mathbf{7}$ & Comparison & 3 & 0.44 \\
\hline $\mathbf{8}$ & Attitude & 1 & 0.14 \\
\hline
\end{tabular}




\begin{tabular}{|l|l|l|l|}
\hline Total & $\mathbf{6 8 0}$ & \\
\hline Average & $\mathbf{6 . 8}$ & $\mathbf{1 3}$ \\
\hline
\end{tabular}

It is evident that the most frequent DMs that students used are those that signal the additive function. The total number of additive markers was 309 out of which the connector 'and' was used 230 times, i.e. (74\%). The other additive markers were 'furthermore, moreover, also, in addition, besides.' The frequent use of the connective 'and' can be easily attributed to the fact that it is the nearest equivalent to the Arabic conjunction 'wa', which is very frequent in formal written discourse. The markers that signal the other functions were much less frequent. The least frequent markers used were those that signal the functions of expressing attitude and comparison. There was only one example of markers used to express attitude that was 'in my opinion.' These results also show that the participants face a considerable difficulty in using DMs and determining their functions in discourse. Table (2) also shows that the students did not use any discourse marker that signals the explanatory function such as "this means, that is to say, in other words".

Comparing the results of the recognition task with those of the production, we can readily notice that the percentage of correct responses in recognition $(50 \%)$ was higher than that of production (39). This result can be attributed to the fact that comprehension or recognition usually develops earlier than production. This finding corroborates what Brown (2000) stated that “... most observational and research evidence points to the general superiority of comprehension over production, and ... even adults perceive more syntactic variation than they actually produce" (pp. 33-34).

\section{Conclusions and recommendations}

Since the sample of the participants used in this study was selected from one university, the study will in no way attempt to generalize the present findings beyond the context of that university. The findings of this research indicate that the participants encountered a serious difficulty in attaining an adequate level of mastery in the recognition and production of DMs. The results reveal that DMs were in general underused or misused. This clearly accounts for the participants' unsatisfactory level of performance and highlights the need to use DMs properly in order to enhance the quality of writing. The overall mastery level of recognition and production did not exceed 50\%. This low level of performance is far from being acceptable for a few reasons. The participants of the study have been studying English for more than 13 years at the primary, secondary and tertiary levels. They have also attained the university admission requirement of obtaining a band score of 5 on the IELTS or a score of 500 on the TOEFL. Furthermore, they studied at least two English language courses at the university. This low level of performance motivates us to conclude that there is a methodological deficiency in the practices of teaching English at schools and universities as well. Besides, we cannot exclude the role of curriculum designers and textbook authors. It seems that DMs, despite their significant roles in developing spoken and written discourse, are not accorded adequate attention in teaching and in textbook 
activities as well. It is, therefore, advisable that the entire process of teaching be reconsidered and the teaching materials be redirected in a way that focuses more on raising students' awareness of the importance of properly using DMs. It is also recommended that textbook writers systematically accord more attention to teaching DMs through different types of activities that develop students' awareness of DMs and their functions in building texts as well as the students' abilities to use them freely in both speaking and writing. The following are illustrative examples of such activities.

\subsection{Awareness exercises}

Activity 1. Read the following paragraph and underline the connectives/DMs. This activity raises the students' awareness of this group of words and phrases. Activity 2. Error Detection: Underline the word or phrase that is not properly used in each of the following sentences/paragraph.

Research has proved that smoking is deadly and carcinogenic. For example, (Nonetheless), $40 \%$ of the population smokes. Our teacher promised to take us on a field trip. However, he changed his mind last week. Peter was warned not to invest all of his savings in the stock market. Consequently (Nevertheless), he invested and lost everything.

Such activities enhance students' knowledge of DMs and their functions in texts.

Activity 3: What is the relationship between a sentence and a preceding one? Which word or phrase signals this relation? I assured my colleague that I would attend his thesis defense. Furthermore, I invited a number of my friends from other colleges.

In such an activity, the teacher asks the students about the relationship between the second sentence and the first. He may guide them through his questions as in: How does S2 relate to S1? Does it show contrast? Does it give a cause? Does it add more information? Which word signals this relationship? This activity should be practiced while teaching reading where students are exposed to paragraphs, essays and longer texts in order to raise their awareness of the roles that DMs play in signaling sentential roles.

\subsection{Production activities}

Activity 1.Circle the letter of the most appropriate word or phrase that best fills in the blank in each sentence.

a. The young girl did not get any medical attention. she died soon.
a. Despite
b. As a result
c. However
d. In this case

b. I've always known Caroline as a mean person.------------, she lent me $\$ 20$ yesterday without me having to ask twice.
a. In other words
b. In fact
c. Moreover
d. Nevertheless

Activity 2. Rewrite the following sentences using the connectors in parenthesis. Make the necessary changes. 
a. The group is popular. The group hasn't reached any gold record yet. (In spite of)

b. Roger works very hard to help his parents. He's also a good student. (In addition)

Activity 3. Use the following DMs in meaningful sentences:

for instance, since, besides, that is to say, despite, in brief, in my opinion

Activity 4. Correction: Students are given sentences that have wrongly used DMs and asked to correct them. Example: It took us a long time to reach the theater downtown in spite of the heavy traffic jam.

\section{Acknowledgement}

We would like to thank IJEAS anonymous reviewers for their suggestions and comments. All remaining errors and shortcomings are our own.

Shehdeh Fareh

University of Sharjah, UAE

Email: shfareh@sharjah.ac.ae

Najib Jarad

University of Sharjah, UAE

Email: njarad@sharjah.ac.ae

Sane Yagi

University of Sharjah, UAE

Email: saneyagi@gmail.com

\section{References}

Al-Hazmi, Sultan. (2006). 'Writing Reflection: Perceptions of Arab EFL Learners'. South Asian Language Review, 16 (2), 36-52.

Al-Jamhoor, Abdulrahman. (2001). 'A Cross-cultural Analysis of Written Discourse of Arabic-Speaking Learners of English'. Journal of King Saud University (Language and Translation), 13 (1), 25-44.

Al-Khuweileh, Abdullah and Ali Al-Shoumali. (2000). 'Writing Errors: A Study of the Writing Ability of Arab Learners of Academic English and Arabic at University'. Language, Culture and Curriculum, 13 (2), 174-183.

Biber, Douglas, Susan Conrad and Geoffrey Leech. (2002). A Student Grammar of Spoken and Written English. London: Longman.

Brown, H. Douglas. (2000). Principles of Language Learning and Teaching. ${ }^{\text {th }}$ ed. New York: Longman.

Carter, Ronald and Michael McCarthy. (2006). Cambridge Grammar of English: A Comprehensive Guide. Cambridge: Cambridge University Press.

Catalán, Rosa Ma Jiménez and Ojeda Juliet Alba. (2014). 'Diagnosis of EFL Learners' Difficulties in the Use of Connectors in a Writing Task: 
Strategies for Remedial Work/Diagnostic'. Didáctica: Lengua y Literatura, 26, 197-216.

Chen, Cheryl Wei-Yu. (2006). 'The Use of Conjunctive Adverbials in the Academic Papers of Advanced Taiwanese EFL Learners'. International Journal of Corpus Linguistics, 11 (1), 113-130.

Davies, Mark. (2008-) The Corpus of Contemporary American English (COCA): 520 million words, 1990-present. Available online at http://corpus.byu.edu/coca/.

Ezza, El-Sadig. (2010). 'Arab EFL Learners' Writing Dilemma at Tertiary Level'. English Language Teaching, 3 (4), 33-39.

Faghih Sabet, A., M. Khodabandehlou, and S. Jahandar. (2013). 'The Impact of Instructing Discourse mMarkers (cohesive devices) on Iranian EFL Learner's Reading Comprehension Ability'. Indian Journal of Fundamental and Applied Life Sciences 3 (3): 273-280.

Fareh, Shehdeh. (2014a). 'Towards a Discourse Grammar in Language Teaching.' International Journal of Arabic-English Studies (IJAES) Vol. 15, 7-26.

Fareh, Shehdeh. (2014b). 'Macrolinguistic Errors in Arab EFL Learners Essays'. Procedia- Social and Behavioral Sciences, 141, pp. 924-933.

Fraser, Bruce. (1999). 'What are Discourse Markers'. Journal of Pragmatics 31, 931-952.

Halliday, Michael Alexander Kirkwood, and Ruqaiya Hasan. (1976) Cohesion in English. London: Longman.

Huddleston, Rodney and Geoffery Pullum. (2002). Cambridge Grammar of the English Language. Cambridge: Cambridge University Press.

Iseni, Arburim, Ali Asbitan Almasaeid, and Mohammad Ali Bani Younes. (2016). 'The Role of Discourse Markers and Cohesive Devices in Writing: EFL Students a Case Study'. ANGLISTICUM. Journal of the Association-Institute for English Language and American Studies 2 (4): 35-48.

Larsen-Freeman, Diane, Marianne Celce-Murcia, Jan Frodesen, Benjamin White, and Howard Alan Williams. (2016). The Grammar Book: Form, Meaning, and Use for English Language Teachers. National Geographic Learning, Heinle Cengage Learning.

Quirk, Randolph, Sydney Greenbaum, Geoffery Leech and Jan Svartvik. (1985). A Comprehensive Grammar of the English Language. London: Longman.

Svartvik, Jan. (1980). 'Well in Conversation'. Studies in English Linguistics for Randolph Quirk, 5, 167-177.

Umair, Naheed. (2011). 'Problems of Multi-Ability Academic English Writing Classes in Arab Countries'. Arab World English Journal, 2 (2), 230-242. 